\title{
Population-Based Research: Breastfeeding Multiple Birth Infants / Twin Research Reviews and News: Perceived Aging in Twins; Separation of Conjoined Twins; School Placement Legislation / Twins in Education, Fashion and Humanitarian Events
}

\author{
Nancy L. Segal \\ Department of Psychology, California State University, United States of America
}

\begin{abstract}
The health benefits of breastfeeding are well known. However, less is known about the frequency and duration of breastfeeding in twins. A population-based study of maternal factors associated with the early cessation of breastfeeding in preterm and term twins is reviewed. This is followed by research reviews and news concerning aging in twins, conjoined twin separation and school legislation for multiple birth children. Twins and quadruplets who have distinguished themselves in the areas of education, fashion design and humanitarian efforts are highlighted.
\end{abstract}

\section{Population-Based Research: Breastfeeding Multiple Birth Infants}

The health benefits of breastfeeding newborn infants are well known. They include reduced risks of allergies, obesity and asthma in infants, and reduced risks of osteoporosis and some cancers in mothers (Baby Center, 2005). However, less is known about the frequency and duration of breastfeeding patterns in preterm and term twins. A population-based study of maternal factors associated with the early cessation of breastfeeding in multiple birth infants was conducted in Sweden by Asa Ostland and colleagues in Sweden (Ostlund, Nordstrom, Dykes, \& Flacking (2010). Sweden's breastfeeding rate $(70 \%)$ is one of the highest in the world.

The study was retrospective in nature. Participants were obtained from two population registers. The first included infants in the Child Health Center (CHC) in the counties of Orebro and Uppsala, who were enrolled between 1993-2001. Mothers were routinely questioned about breastfeeding practices during scheduled visits. Approximately 57,000 infants were identified through the $\mathrm{CHC}$, with data obtained on approximately 55,000 from the Medical Birth Registry (MBR). At this stage, only mothers of twins were selected, yielding a final sample of 1,657 twins. This group was comprised of 695 twins born prematurely (before 37 weeks gestation) and 962 twins born at term (at or later than 37 weeks gestation). Breastfeeding data were lacking for 13 twins, a factor that explains the uneven number of twins under study.

Breastfeeding in Sweden has been recorded on a national basis for a number of decades. The investigators examined the frequency of breastfeeding when twin infants were 2, 4, 6, 9 and 12 months of age. Maternal variables included educational level (upper secondary school or less, or higher education), parity (primiparous or multiparous), age (four groups: $\leq$ 23, 24-28, 29-33, $\geq 34$ ), ethnicity (born in Sweden or born outside Sweden), smoking (smoking or not smoking at the first antenatal visit), marital status (single or cohabitating) and method of delivery (vaginal or Csection).

The gestational age for preterm twins ranged between 24-36 weeks, with a median age of 35 weeks. The birthweight for these twins ranged between 483-3,735 g, mean $=2,211$,

Address for correspondence: Nancy L. Segal, Department of Psychology, California State University, Fullerton, CA 92834, USA. E-mail: nsegal@Exchange.FULLERTON.EDU 
$S D=566$. The gestational age for term twins ranged between 37-43 weeks, with a median age of 38 weeks. The birthweight for these twins ranged between 1,612-4,220 g, mean = 2,908, $S D=409$.

Fewer preterm twins were breastfed at 2, 4, 6 and 9 months, compared to term twins. Preterm twins also had a higher risk of being weaned before 2 months of age. However, at age 12 months, there was no difference in breastfeeding frequency between preterm $(6 \%)$ and term twins $(6 \%)$. The percentage of mothers who stopped breastfeeding between the 2-4 month, 4-6 month, 6-9 month and 9-12 month intervals did not differ between the two twin groups.

Several maternal factors were individually associated with the earlier cessation of breastfeeding in preterm twins: lower educational level, younger age and smoking at the first antenatal visit. However, in adjusted logistic regression analyses in which education, age and smoking were mutually adjusted, mothers with less education or who smoked were more likely to discontinue breastfeeding before the twins were 6 months of age. The association between age and weaning became non-significant.

These analyses were repeated for term twins. The unadjusted findings showed that less education, being younger than age 28 , smoking and being primiparous were individually linked to weaning before 6 months. When these four maternal factors were adjusted, it was found that less education, age younger than 23 years, smoking or being primiparous continued to predict cessation of breastfeeding before twins turned 6 months of age.

Approximately $80 \%$ of the mothers of both preterm and term twins studied had engaged in breastfeeding before their infants were 2 months old. However, a substantial proportion of these mothers had stopped breastfeeding before 6 months. Drawing upon other studies, the investigators sug- gested several explanations for mothers' decisions: breastfeeding is time-consuming and stressful; stress is associated with reduced oxytocin levels that can adversely affect breastfeeding and/or fathers may not have been sufficiently supportive.

It was also found that mothers with less education tended to discontinue breastfeeding before mothers with higher levels of education. It was suggested that less-educated women may feel less in control and experience greater stress. Multiparity was linked with longer periods of breastfeeding in term twins, but shorter periods of breastfeeding in preterm twins. Having other children besides preterm twins may produce greater exhaustion and psychological upset.

This study will, hopefully, be repeated using other populations. Identifying factors associated with continued and discontinued breastfeeding in twins can improve both infant and maternal health and wellbeing.

\section{Twin Research Reviews and News}

\section{$\overline{\text { Perceived Aging in Twins }}$}

Dr Kaare Christensen and his colleagues in the United States, New Jersey, England, Germany and The Netherlands have produced an important and creative twin study on perceived aging as a marker of biological aging (Christensen, Thinggaard, McGue, Rexbye, Hjelmborg, Aviv, et al., 2009). Ratings of perceived age were made of photographs of 387 same-sex twin pairs who had participated in the Longitudinal Study of Aging Danish Twins (LSADT). Raters included 20 female geriatric nurses, 10 male student teachers and 11 older women. Twins' years of survival were obtained through the Danish Civil registration system. Measures of physical functioning included self-reported physical strength (e.g., walking up two flights of stairs) and grip strength (values on a Smedley Dynamometer). Cognitive functioning measures included the mini-mental state examination and five short cognitive tests. Leucocyte telomere length was assessed, given that shorter length is associated with diseases related to aging and to mortality.

Results showed that perceived age was significantly associated with survival, even after controlling for chronological age, sex and the rearing environment. Furthermore, the relationship between perceived age and survival was maintained even after controlling for physical and cognitive functioning. It was especially interesting that the greater the co-twin difference in perceived age, the greater the likelihood that the older looking twin died first. Perceived age, when controlled for chronological age and sex, also correlated significantly with physical and cognitive functioning, and with leucocyte telomere length. Thus, perceived age appears to be a valid index of patient health.

The paper is accompanied by a pair of composite photographs. One picture displays the average appearance of ten sets of younger looking seventyyear-old twins, while the other picture displays the older looking co-twins.
The difference between the two final images is striking.

\section{Separation of Conjoined Twins}

Conjoined twins Krishna and Trishna, connected at the head, were successfully separated in November 2009, in Australia. They were born in Bangladesh - an aid worker had seen them when they were infants and had arranged to bring them to Australia for surgery. Their mother had placed them in an orphanage, in the capital of Dhaka, when she could no longer care for them. The operation took place at the Royal Children's Hospital when the twins were nearly 3 years old. The surgical procedures were complex because the twins shared brain tissue.

The twins are doing well at present and are beginning to interact with one another. Trishna is eating on her own for the first time; previously, she had received her nutrition from her sister. It is likely that the twins will remain in Australia with their mother. 


\section{School Placement Legislation}

On March 8, 2010, Gwen Adams informed me that the Tennessee Senate had passed legislation granting parents a significant voice in the school placement of their twin children. There has been considerable progress in this regard. The current state-side count is: enacted legislation (12 states); sponsored legislation (10 states); passed resolutions allowing parental input (2 states); and awaiting sponsorship (10 states). These results are posted on the national website, www.twinslaw.com; note that Tennessee has not yet been moved into its new category.

Ms Adams wrote: 'They gave us honored seats by the senators instead of being in the balcony. They introduced our families and when it was time to vote, our Senator Diane Black let my sons come to her senate seat and push the button to put the vote in
... They got to make history for twins tonight.'

The identical Adams twins are 7 years old. Braden's vaginal birth pulled Connor's cord, necessitating an emergency C-section for the second twin. Ms Adams later wrote, 'If I were to advocate for twins again, it would be that a final ultrasound be done at the birth of all multiples to be certain of their position in the womb'.

\section{Twins in Educational, Sports and Humanitarian Events}

\section{Quaduplets at Yale}

Kenny, Martina, Ray and Carol Crouch are African-American quadruplets from Danbury, Connecticut (Steinberg, 2009). In December 2009, all four siblings were accepted into the 2014 class of Yale University, in New Haven. The quads were born two months prematurely - Ray remained in the neonatal unit for over 4 months. Despite the quads' inauspicious start, their high school class rankings ranged from 13 (Kenny) to 46 (Martina) out of a class of 632 students. Carol obtained a perfect score of 800 on the verbal portion of the SAT. Yale's Dean of Admissions, Jeffrey Brenzel, claims that family relationships are not considered in accepting new students and that all four Crouch quads merited admission to Yale on their own.

The quads' parents are Steven and Caroline Crouch. Steven is a case manager for Connecticut's Department of Mental Health and Caroline is studying for a Master's Degree in Social Work. Financial concerns will strongly influence where the quads will ultimately go to college. Dean Brenzel says that Yale considers number of other children in the family when making financial aid decisions. The quads' college choices are still unknown.

Pairing the quads in different ways yields four sets of fraternal opposite-sex twins. Judging from the photographs, the two males and two females also appears to be nonidentical. In view of genetic influences on ability, motivation and achievement, it is somewhat surprising that all four siblings have succeeded at such high levels. (Male quadruplets currently attend MIT, but the zygosity of the members is unknown.) If the quads were identical (as are the female twins discussed immediately below), their matched intellectual achievements would be more expected.

\section{Valedictorian and Salutatorian Twins}

Woodbury High school in southern California honored identical female twins, Anjali and Praveen Bains, as their 2009 valedictorian and salutatorian, respectively (Kispert, 2009). The twins appear to be identical based on inspection of their photograph. They are attending Columbia University and the University of Pennsylvania. Both twins plan had planned to study bio-engineering.

The twins claim that their motivation to learn comes from themselves, not from their parents. However, they rarely study together because they are very close and will distract one another. They are not rivals - the fact that both could not be valedictorians was not a problem. This degree of selflessness is a hallmark of identical twinship.

\section{Twin Sports Fashion Designers}

Just as the Vancouver Olympic games were beginning, I saw NBC news coverage of Canadian twin fashion designers, Dean and Dan Caten (NBC,
2009). The twins live in Milan, Italy, and are co-hosts and judges of Launch My Line, a recent competition reality show. They were chosen to design the Canadian athletes' outfits for the opening ceremony.

Researching this pair revealed that they were born in Toronto in 1964, the youngest of nine children (Wikipedia, 2010). In 1983 they both studied fashion at the Parsons New School for Design in New York, but stayed only one semester before returning to Toronto. In 1986, a financial backer enabled them to launch their first signature collection for women, called DEanDan. They then worked for several fashion companies before moving to Milan in 1991. Their fashion runway shows are aptly called Dsquared2. Today, they design clothes for men and women, as well as cosmetics and perfumes. In September 2009, they received a star on Canada's Walk of Fame, in Toronto.

\section{Identical Twin Doctors in Haiti}

The January 12, 2010 earthquake in Haiti continues to demand relief efforts by many. A recent $\mathrm{CNN}$ news program featured Haitian identical twin doctors, Jerry and Marlo Bitar (CNN, 2010). CNN physician Dr. Sanjay Gupta and staff followed the twins for two weeks as they cared for their injured fellow citizens. The Bitars are apparently indistinguishable with the exception of a mole on one twin. They helped the Haitian people by keeping their clinic offices open even 
when they ran out of beds-and even though their patients could not pay. The twins have been called heroes, something they emphatically deny. They feel that their country needs them.

There were 2,000 doctors in Haiti before the earthquake. Haiti graduates approximately 80 doctors per year, hardly enough to care for the $9,000,000$ people who were there before the disaster. However, some doctors have left the country, and medical schools and other facilities were destroyed in the quake. Fortunately, the twins have no intention of leaving.

\section{References}

Baby Center. (2005). How breastfeeding benefits you and your baby. Available at www.babycenter.com.

Christensen, K., Thinggaard, M., McGue, M., Rexbye, H., Hjelmborg, J., Aviv, A., et al. (2009). Perceived age as clinically useful biomarker of ageing: cohort study. British Medical Journal, 339 , b5262.

CNN. (2010, 30 January 30). Heroes saving Haiti. Anderson Cooper 360 Degrees (CNN).

Kispert, A. (3 June, 2009). It's all in the family for twins. Woodbury Bulletin (Special Section), p. 11.
NBC TV News (2009, February 12). Olympics coverage: Dean and Dan Caten, 8:23 am.

Ostlund, A., Nordstrom, M., Dykes, F., \& Flacking, F. (2010). Breastfeeding in preterm and term twins - Maternal factors associated with early cessation: A population-based study. Journal of Human Lactation, doi: $10.1177 /$ 0809334409359627.

Steinberg, J. (2009, December 18). Boola Boola, Boola, Boola: Yale says yes 4 times. New York Times, p. A-1.

Wikipedia (2010, February 12). Dean and Dan Caten. Available at en.wikipedia. org/wiki/Dean_and_Dan_Caten.

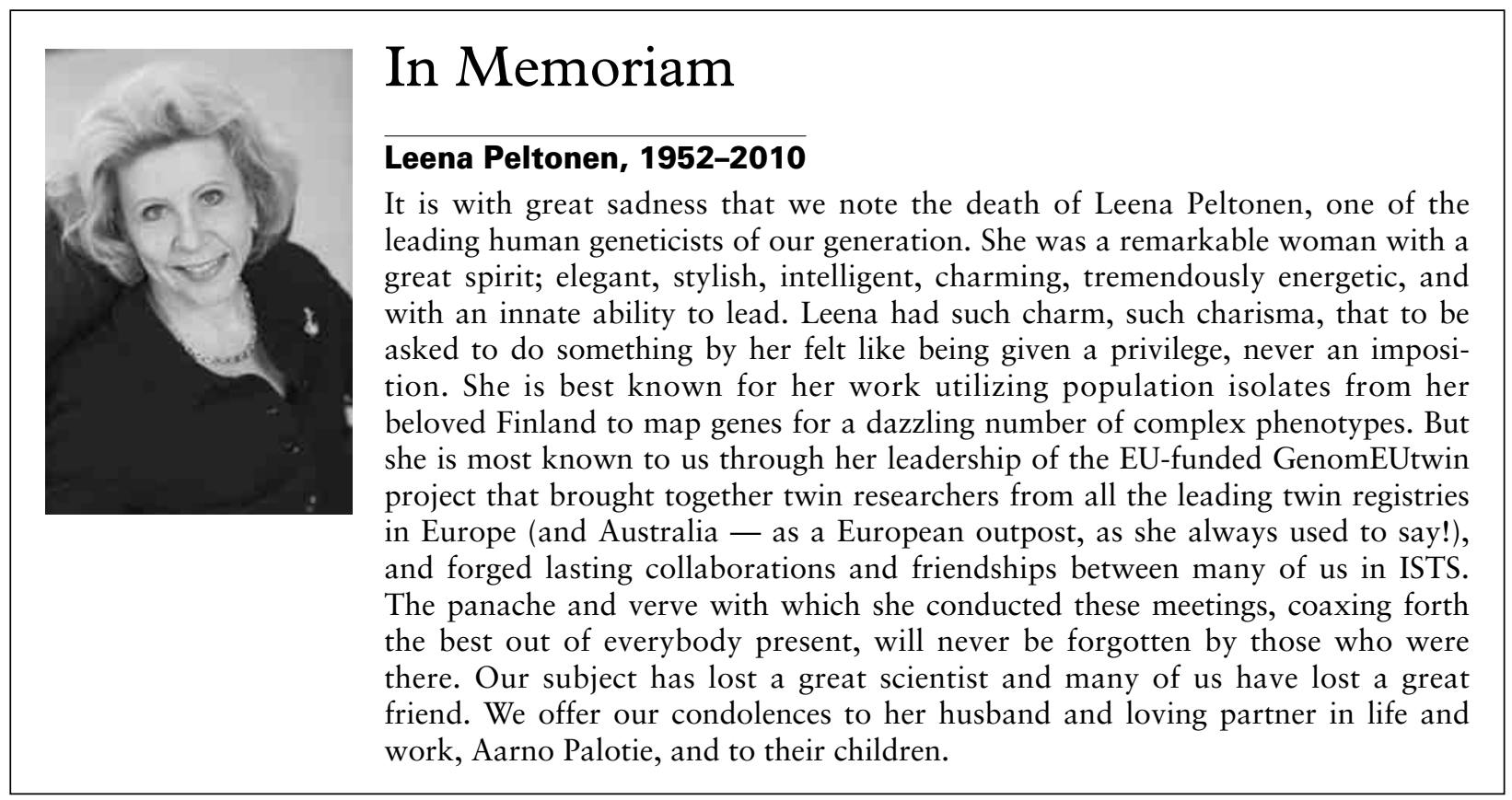

